\title{
Predictors of Readmission after Inpatient Plastic Surgery
}

\author{
Umang Jain ${ }^{1}$, Christopher Salgado ${ }^{2}$, Lauren Mioton ${ }^{3}$, Aksharananda Rambachan ${ }^{1}$, John YS Kim ${ }^{1}$ \\ ${ }^{1}$ Division of Plastic and Reconstructive Surgery, Northwestern University Feinberg, School of Medicine, Chicago, IL; ${ }^{2}$ Department of Plastic \\ Surgery, UH Case Medical Center, Cleveland, OH; ${ }^{3}$ Vanderbilt School of Medicine, Nashville, TN, USA
}

Background Understanding risk factors that increase readmission rates may help enhance patient education and set system-wide expectations. We aimed to provide benchmark data on causes and predictors of readmission following inpatient plastic surgery.

Methods The 2011 National Surgical Quality Improvement Program dataset was reviewed for patients with both "Plastics" as their recorded surgical specialty and inpatient status. Readmission was tracked through the "Unplanned Readmission" variable. Patient characteristics and outcomes were compared using chi-squared analysis and Student's t-tests for categorical and continuous variables, respectively. Multivariate regression analysis was used for identifying predictors of readmission.

Results A total of 3,671 inpatient plastic surgery patients were included. The unplanned readmission rate was $7.11 \%$. Multivariate regression analysis revealed a history of chronic obstructive pulmonary disease (COPD) (odds ratio [OR], 2.01; confidence interval [Cl], 1.123.60; $\mathrm{P}=0.020)$, previous percutaneous coronary intervention $(\mathrm{PCl})(\mathrm{OR}, 2.69 ; \mathrm{Cl}, 1.21-5.97$; $\mathrm{P}=0.015)$, hypertension requiring medication $(\mathrm{OR}, 1.65 ; \mathrm{Cl}, 1.22-2.24 ; \mathrm{P}<0.001)$, bleeding disorders ( $\mathrm{OR}, 1.70 ; \mathrm{Cl}, 1.01-2.87 ; \mathrm{P}=0.046)$, American Society of Anesthesiologists (ASA) class 3 or $4(\mathrm{OR}, 1.57 ; \mathrm{Cl}, 1.15-2.15 ; \mathrm{P}=0.004)$, and obesity (body mass index $\geq 30)(\mathrm{OR}, 1.43$; $\mathrm{Cl}, 1.09-1.88, \mathrm{P}=0.011)$ to be significant predictors of readmission.

Conclusions Inpatient plastic surgery has an associated $7.11 \%$ unplanned readmission rate. History of COPD, previous $\mathrm{PCl}$, hypertension, ASA class 3 or 4, bleeding disorders, and obesity all proved to be significant risk factors for readmission. These findings will help to benchmark inpatient readmission rates and manage patient and hospital system expectations.

Keywords Inpatients / Surgery, plastic / Patient readmission
Correspondence: John YS Kim Division of Plastic and Reconstructive Surgery, Northwestern University, Feinberg School of Medicine, 675 North St. Clair Street, Galter Suite 19-250, Chicago, IL 60611, USA Tel: +1-312-695-6022

Fax: +1-312-695-5672

E-mail: jokim@nmh.org
Lauren M. Mioton is funded by a research scholarship through Vanderbilt University School of Medicine by NIH CTSA Grant UL1RR024975.

No potential conflict of interest relevant to this article was reported.

\section{INTRODUCTION}

Hospital readmissions are of particular interest because of their known contribution to elevated health care costs and potential use as a quality measure $[1,2]$. Various studies have shown that readmissions impose a high financial burden on healthcare sys- tems in Europe and the United States [3-6]. In 2011, 6.5\% of hospitalized patients in the United Kingdom were readmitted within 30 days, incurring costs of $\$ 2.4$ billion to the National Health Service [7]. As a recent MedPAC Medicare analysis revealed, readmissions account for $17.6 \%$ of Medicare costs in the United States-or $\$ 15$ billion in expenditures annually-out 
of which $\$ 12$ billion is potentially preventable [8,9]. Similar increases in healthcare costs may also be seen with readmissions outside of Medicare coverage. As such, an effort to develop a more cost-effective healthcare system through readmission reduction has led global payers and policymakers to reform sectors that are expensive and offer opportunities for quality improvement.

The most prominent example of targeting readmissions for cost and quality reform is the recent establishment of the Hospital Readmissions Reduction Program in the United States, which enacts penalties for hospitals that have above-average hospital readmission rates [10,11]. While this endeavor focuses on certain medical conditions, its development should raise awareness regarding readmissions in all fields [12]. Hospital readmissions following surgical procedures certainly factor in to higher medical bills, and investigating the potential causes for this adverse event may enhance our ability to prevent future occurrences [13]. Data concerning readmissions after inpatient plastic surgery are presently limited. Therefore, we endeavored to identify benchmark rates and causes for readmission following inpatient plastic surgery.

Large-scale outcomes databases have contributed to detailed and generalizable data analysis concerning surgery in the past decade. It has only been recently, however, that readmissions data have been tracked. We drew upon data from the National Surgical Quality Improvement Program (NSQIP) databaserepresenting more than 400 hospitals-to investigate readmissions after inpatient plastic surgery.

\section{METHODS}

A retrospective analysis was performed on data collected from the 2011 NSQIP participant use files. The data collection methods for the NSQIP have been previously described in detail [14-16]. In brief, 240 variables, including patient demographics, comorbidities, preoperative laboratory values, perioperative details, and 30-day risk-adjusted postoperative outcomes, were prospectively collected for each patient. To ensure accuracy, certified nurse reviewers are rigorously trained to collect patient information according to standardized definitions, and the data are regularly audited.

Patients undergoing inpatient plastic surgery were identified using the Inpatient/Outpatient and Surgical Specialty variables. All plastic surgery procedures, both cosmetic and reconstructive, were included. Patients with incomplete demographic data (such as no gender information) were excluded. A total of 3,671 inpatient plastics patients were identified.

\section{Outcomes}

The primary outcome of our study was 30-day unplanned readmission. The NSQIP incorporated a new variable entitled "Unplanned Readmission" into its 2011 dataset, which was defined as "readmission (to the same or another hospital) for a postoperative occurrence likely related to the principal surgical procedure" within 30 days of the procedure. We utilized the "Unplanned Readmission" variable to calculate readmission rates and conduct a more focused investigation into predictors of readmission.

\section{Risk factors}

Patient demographics and medical co-morbidities were tracked as potential risk factors. The patient demographics collected included sex, race, and age $>50$ years, as well as various clinical characteristics such as smoking, alcohol use, chemotherapy/ radiotherapy in the previous 30 days, previous surgery, obesity, diabetes, dyspnea, chronic obstructive pulmonary disease (COPD), bleeding disorder, and hypertension requiring medication. Medical complications documented by the NSQIP include deep vein thrombosis (DVT), pulmonary embolism (PE), unplanned re-intubation, ventilator dependence ( $>48$ hours), renal insufficiency, acute renal failure, coma, stroke, cardiac arrest, myocardial infarction, peripheral nerve injury, pneumonia, urinary tract infection, bleeding requiring transfusion, and sepsis/septic shock. Further, surgical complications recorded by the NSQIP include superficial, deep, and organ/space surgical site infection (SSI), prosthesis failure, and wound dehiscence.

\section{Statistical analysis}

Rates were determined for the five most common inpatient plastic surgery procedures independent of readmission rates (Table 1): breast reconstruction with tissue expander (Current Procedural Terminology code [CPT] 19357), muscle, myocutaneous or fasciocutaneous flap (CPT 15734), breast reconstruction with free flap (CPT 19364), reduction mammoplasty

Table 1. Hospital readmission rates associated with the top five most common inpatient plastic surgery procedures ${ }^{\text {a) }}$

\begin{tabular}{|c|c|c|c|}
\hline $\begin{array}{l}\text { CPT } \\
\text { code }\end{array}$ & Number & Description & $\begin{array}{l}\text { Readmission } \\
\text { rate }(\%)\end{array}$ \\
\hline 19357 & 444 & $\begin{array}{l}\text { Breast reconstruction with tissue } \\
\text { expander }\end{array}$ & 7.2 \\
\hline 15734 & 329 & $\begin{array}{l}\text { Muscle, myocutaneous, or } \\
\text { fasciocutaneous flap (to the trunk) }\end{array}$ & 10.6 \\
\hline 19364 & 324 & Breast reconstruction with free flap & 5.9 \\
\hline 19318 & 254 & Reduction mammaplasty & 1.6 \\
\hline 15830 & 233 & Panniculectomy & 7.3 \\
\hline
\end{tabular}


Table 2. The top 5 inpatient plastic surgery procedures with the most unplanned readmissions

\begin{tabular}{|lccc|}
\hline Procedure & $\begin{array}{c}\text { CPT } \\
\text { code }\end{array}$ & $\mathbf{n}$ & $\begin{array}{c}\text { \% of total } \\
\text { unplanned } \\
\text { readmissions }\end{array}$ \\
\hline $\begin{array}{l}\text { Muscle, myocutaneous, or fasciocutaneous } \\
\text { flap (to the trunk) }\end{array}$ & 15734 & 35 & 13.4 \\
$\begin{array}{l}\text { Breast reconstruction with tissue expander } \\
\text { Breast reconstruction with free flap }\end{array}$ & 19357 & 32 & 12.3 \\
$\begin{array}{l}\text { Panniculectomy } \\
\text { Muscle, myocutaneous, or fasciocutaneous } \\
\text { flap (to the lower extremity) }\end{array}$ & 15364 & 19 & 7.3 \\
\hline CPT, Current Procedural Terminology. & & 17 & 6.5 \\
\hline
\end{tabular}

Table 3. Characteristics of patients following inpatient plastic surgery

\begin{tabular}{|c|c|c|c|}
\hline $\begin{array}{l}\text { Population } \\
\text { demographics }\end{array}$ & $\begin{array}{l}\text { No unplanned } \\
\text { readmission }\end{array}$ & $\begin{array}{l}\text { Unplanned } \\
\text { readmission }\end{array}$ & P-value \\
\hline No. of patients & 3,410 & 261 & \\
\hline Sex & & & $0.032^{\mathrm{a})}$ \\
\hline Male & $805(23.6)$ & $77(29.5)$ & \\
\hline Female & $2,605(76.4)$ & $184(70.5)$ & \\
\hline Race & & & 0.12 \\
\hline White & $2,386(70.0)$ & $201(77.0)$ & \\
\hline Black & $391(11.5)$ & $22(8.4)$ & \\
\hline Asian & $86(2.5)$ & $5(1.9)$ & \\
\hline Other & $547(16.0)$ & $33(12.6)$ & \\
\hline Age (yr) & $50.83 \pm 13.94$ & $55.77 \pm 14.36$ & 0.509 \\
\hline Body mass index $\left(\mathrm{kg} / \mathrm{m}^{2}\right)$ & $28.7 \pm 7.70$ & $30.95 \pm 7.78$ & $0.032^{\mathrm{a})}$ \\
\hline \multicolumn{4}{|l|}{ Clinical characteristics } \\
\hline Smoking & $520(15.2)$ & $47(18.0)$ & 0.235 \\
\hline Alcohol & $46(1.3)$ & $2(0.8)$ & 0.319 \\
\hline Chemotherapy $<30$ day & $65(1.9)$ & $4(1.5)$ & 0.467 \\
\hline Radiotherapy $<90$ day & $25(0.7)$ & $1(0.4)$ & 0.429 \\
\hline Previous operation $<30$ day & $198(5.8)$ & $18(6.9)$ & 0.24 \\
\hline Obesity & $1,167(34.2)$ & $125(47.9)$ & $<0.001^{\text {a) }}$ \\
\hline Diabetes & $176(5.2)$ & $35(13.4)$ & $<0.001^{\text {a) }}$ \\
\hline Dyspnea & $157(4.6)$ & $21(8.0)$ & $0.013^{\mathrm{a})}$ \\
\hline $\begin{array}{l}\text { Chronic obstructive } \\
\text { pulmonary disease }\end{array}$ & $81(2.4)$ & $21(8.0)$ & $<0.001^{\mathrm{a})}$ \\
\hline Bleeding disorder & $111(3.3)$ & $25(9.6)$ & $<0.001^{\text {a) }}$ \\
\hline $\begin{array}{l}\text { Hypertension requiring } \\
\text { medication }\end{array}$ & $1,073(31.5)$ & $138(52.9)$ & $<0.001^{\text {a) }}$ \\
\hline
\end{tabular}

(CPT 19318), and panniculectomy (CPT 15830). Readmission rates after inpatient plastic surgery were calculated for each specific type of surgery (categorized by CPT code) and ranked by the number of readmission occurrences (Table 2). Patient demographics, risk factors, and postoperative outcomes were calculated through frequency analysis (Table 3).

Multivariate logistic regression models were used for determining predictors of unplanned readmission (Table 4). HosmerLemeshow (HL) tests for calibration were computed to assess
Table 4. Summary of correlates of readmission from multivariate regression

\begin{tabular}{|c|c|c|c|}
\hline \multirow[b]{2}{*}{ Variable } & \multicolumn{3}{|c|}{ Readmission } \\
\hline & $\begin{array}{l}\text { Odds } \\
\text { ratio }\end{array}$ & $\begin{array}{l}\text { 95\% Confi- } \\
\text { dence interval }\end{array}$ & P-value \\
\hline Gender (male) & 1.023 & $0.744-1.406$ & 0.891 \\
\hline Diabetes & 1.223 & $0.851-1.759$ & 0.277 \\
\hline Dyspnea & 0.697 & $0.397-1.223$ & 0.208 \\
\hline Functional status prior to surgery & 1.114 & $0.708-1.754$ & 0.640 \\
\hline $\begin{array}{l}\text { Chronic obstructive pulmonary } \\
\text { disease }\end{array}$ & 2.008 & $1.118-3.604$ & $0.020^{\mathrm{a})}$ \\
\hline Congestive heart failure & 1.582 & $0.655-3.819$ & 0.308 \\
\hline $\begin{array}{l}\text { Prior percutaneous coronary } \\
\text { intervention }\end{array}$ & 2.686 & $1.208-5.972$ & $0.015^{\text {a) }}$ \\
\hline Hypertension & 1.652 & $1.218-2.241$ & $0.001^{\text {a) }}$ \\
\hline Dialysis & 1.510 & $0.665-3.429$ & 0.324 \\
\hline Wound infection & 1.055 & $0.736-1.514$ & 0.770 \\
\hline Steroid use & 1.477 & $0.781-2.794$ & 0.231 \\
\hline Bleeding disorder & 1.701 & $1.009-2.865$ & $0.046^{a)}$ \\
\hline Sepsis & 0.778 & $0.432-1.399$ & 0.401 \\
\hline $\begin{array}{l}\text { American Society of } \\
\text { Anesthesiologists Class } 3 \text { or } 4\end{array}$ & 1.573 & $1.154-2.146$ & $0.004^{\mathrm{a})}$ \\
\hline Age $>50$ & 1.054 & $0.784-1.417$ & 0.727 \\
\hline Obesity (body mass index > 30) & 1.427 & $1.086-1.875$ & $0.011^{\text {a) }}$ \\
\hline
\end{tabular}

the goodness of fit model. Variables with fewer than 10 events were excluded from the final analyses. All analyses were performed using SPSS ver. 20.0 (IBM Corp., Armonk, NY, USA).

\section{RESULTS}

A total of 3,671 inpatient plastic surgery cases were extracted from the 2011 NSQIP database. Two-hundred and sixty-one (7.11\%) patients suffered an unplanned readmission within 30 days of their primary surgical procedure. The five most common inpatient plastic surgery procedures and their associated readmission rates are listed in Table 1. Muscle, myocutaneous, or fasiocutaneous flap to the trunk (CPT 15734) had the highest readmission rate, at $10.6 \%$ and reduction mammoplasty (CPT 19318) had the lowest rate, at $1.6 \%$.

There were 102 surgical complications and 84 medical complications in the patients that were readmitted. The most common surgical complication was superficial SSI. Of the 37 cases of superficial SSI, 33 had wound classifications of "Clean," 3 of "Clean/Contaminated," and 1 of "Dirty/Infected." Other surgical complications included deep incisional SSI, wound disruption, organ space SSI, and graft/prosthesis failure. The most prevalent medical complication was bleeding requiring transfusion followed by sepsis/septic shock, PE, DVT, and urinary tract infection. 
Fig. 1. Surgical specialty (inpatient) versus readmission rate

Inpatient readmission rates are compared across various surgical specialties.

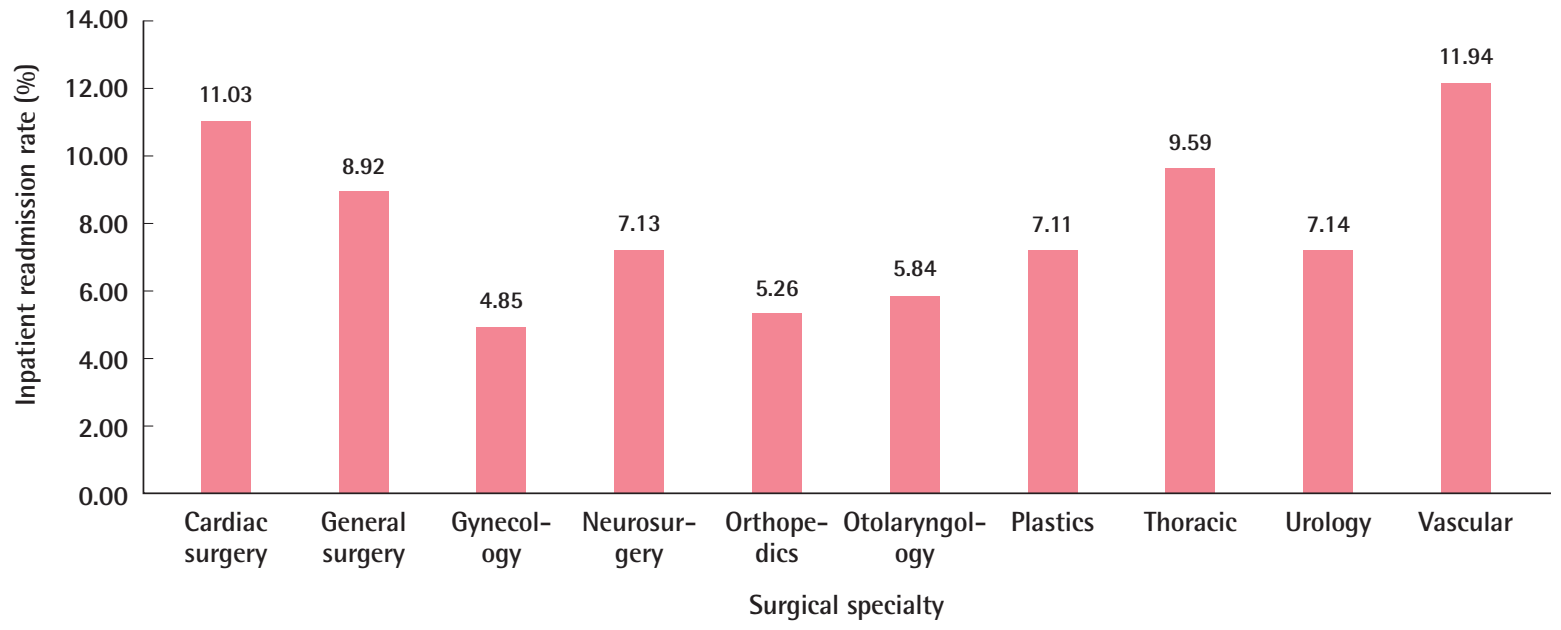

Risk-adjusted multivariate logistic regression identified six significant predictors for readmission following inpatient surgery: history of COPD, previous percutaneous coronary intervention (PCI), hypertension requiring medication, bleeding disorders, American Society of Anesthesiologists (ASA) class 3 or 4, and obesity. Patients with a previous PCI had the highest risk of readmission with an odds ratio (OR) of 2.69 (95\% confidence interval [CI], 1.21-5.97; P = 0.015), followed by a history of COPD (OR, 2.01; CI, 1.12-3.60; $\mathrm{P}=0.020)$, bleeding disorder (OR, 1.70; CI, 1.01-2.87; $\mathrm{P}=0.046)$, hypertension ( $\mathrm{OR}, 1.65$; $\mathrm{CI}, 1.22-2.24$; $\mathrm{P}<0.001)$, ASA class 3 or 4 (OR, 1.57; CI, 1.15-2.15; P =0.004), and obesity (OR, 1.43; CI, 1.09-1.88; $\mathrm{P}=0.011)$. The HL statistic calculated for the multivariate logistic regression was 0.627 , implying that the model's estimates fit the data at an acceptable level.

\section{DISCUSSION}

As the focus on improved patient care and cost reductions continues in healthcare, detailed surgical outcomes studies are needed to help identify those patients most at risk for complications and readmission-unwanted and costly events. Analyzing surgical outcomes data can aid in isolating the significant predisposing factors and procedures most likely to lead to readmissions. Consequently, insurance companies and hospitals may be able to assemble and concentrate resources on selected pre-determined high-risk patients in hopes of driving down readmissions and their associated expenses through reductions in complications.

Our study found that $7.11 \%$ of patients undergoing inpatient plastic surgery were readmitted within 30 days after their initial procedure for a non-planned event. This rate was lower than that of inpatient general, vascular, thoracic, and cardiac surgery, but higher than that of inpatient gynecological, otolaryngologic, and orthopedic procedures (Fig. 1). While it is difficult to discern the exact reasons for such variances in readmission, this adverse event was likely impacted in part by the surgical invasiveness associated with each field and the differing anatomic regions addressed by certain procedures. In particular, general surgery operations are often more invasive than plastic surgery procedures, which tend to focus on the soft tissues and rarely enter the abdominal cavity. Therefore, general surgery procedures have a greater focus on anatomic regions at a higher risk of bacterial contamination. In contrast, gynecologic operations frequently rely on laparoscopic techniques that reduce the exposure of operative sites to contaminated environments and reduce the operative time. Further, otolaryngologic procedures centered on the face may be less prone to complications than other anatomic regions, thereby reducing the likelihood for complicationspecific readmissions.

The unplanned readmission rate of $7.11 \%$ associated with inpatient plastic surgery was higher than the $1.94 \%$ rate seen in outpatient plastic surgery procedures from the same dataset [17]. This may be expected as individuals receiving surgery in an outpatient setting are often healthier at baseline and have a corresponding lower risk for subsequent complications. Moreover, outpatient surgeries tend to be less invasive with shorter operative times-factors that contribute to the relative safety of these procedures and may confer an inherent lower likelihood for adverse events.

SSIs proved to be the most common surgical complication 
noted in our readmitted cohort. This is not surprising as plastic surgery procedures often deal with the superficial soft tissues, and surgical site infections have proven to be a common occurrence: approximately half a million SSIs occur in the United States every year and incur a total cost of $\$ 10$ billion. Patients prone to SSIs according to previous studies share some of the same risk factors with our patient cohort as well, including obesity and intraoperative transfusions $[18,19]$. Consistency of risk factors across patient populations should allow for improved patient education and possibly even more enhanced patient selection.

Multivariate regression analysis revealed that previous percutaneous intervention, history of COPD, hypertension requiring medication, bleeding disorder requiring transfusion, ASA classification of 3 or 4 , and obesity were significant predictors of unplanned readmission. Patients with a previous $\mathrm{PCI}$ had the highest risk of readmission with an OR of 2.69 (95\% CI, 1.21-5.97; $\mathrm{P}=0.015$ ). Prior studies have shown that patients undergoing PCI can suffer from various complications requiring readmission to the hospital, including complications directly related to the PCI; such complications include in-stent thrombosis, vascular access, cardiac complications such as unstable angina and congestive heart failure, and non-cardiac issues such as infection or sepsis [20]. The other predictors of readmission listed in this study have also been connected to increased rates of morbidity and mortality through a number of investigations. Therefore, their subsequent connection to readmissions may not be surprising. Knowledge of such factors specific to readmission after inpatient plastic surgery may help improve patient education and guide patient expectations, particularly re-consideration of early and untimely discharge. Further, those deemed most likely to incur a readmission on the basis of the aforementioned risk factors may be isolated by medical professionals; insurance companies and hospitals alike could then concentrate more resources on this select population, possibly reducing predicted complications and readmission [21,22].

The power of the NSQIP database enhances the generalizability of the results obtained in this study. It features a large, geographically diverse patient population and tracks numerous demographic variables and postoperative outcomes. However, the database is limited in that the outcomes are only reported for 30 days after surgery, possibly leading to under-reporting of complications. It has been suggested that monitoring patients for a minimum of 90 days to one year would capture more of the pertinent outcomes in plastic surgery $[23,24]$. Further, even though it has been independently validated, the NSQIP just began capturing readmissions data in 2011 [25]. As it continues to track these data in the future, we will be able to generate better conclusions about unplanned readmissions in inpatient plastic surgery. Furthermore, the database may not capture all variables that factor into hospital readmission. Nevertheless, this robust database provides a valid measure of the outcomes associated with inpatient plastic surgery and the preoperative comorbidities these patients have that predispose them to return to the hospital within 30 days after their surgery.

In conclusion, unplanned readmission after inpatient plastic surgery has a rate of $7.11 \%$. Previous percutaneous intervention, history of COPD, hypertension requiring medication, bleeding disorder requiring transfusion, ASA classification of 3 or 4 , and obesity are independent predictors of readmission. Benchmarking readmission rates and causes of readmission after inpatient plastic surgery may provide a platform for further risk reduction efforts and set system-wide expectations.

\section{REFERENCES}

1. Bisognano M, Boutwell A. Improving transitions to reduce readmissions. Front Health Serv Manage 2009;25:3-10.

2. Fischer JP, Wes AM, Nelson JA, et al. Factors associated with readmission following plastic surgery: a review of 10,669 procedures from the 2011 American College of Surgeons National Surgical Quality Improvement Program data set. Plast Reconstr Surg 2013;132:666-74.

3. Chambers $M$, Clarke A. Measuring readmission rates. BMJ 1990;301:1134-6.

4. Westert GP, Lagoe RJ, Keskimaki I, et al. An international study of hospital readmissions and related utilization in $\mathrm{Eu}-$ rope and the USA. Health Policy 2002;61:269-78.

5. Saltman RB, Figueras J. Analyzing the evidence on European health care reforms. Health Aff (Millwood) 1998;17:85-108.

6. Ham C, Brommels M. Health care reform in The Netherlands, Sweden, and the United Kingdom. Health Aff (Millwood) 1994;13:106-19.

7. The Burrill Report, Qualcomm Life. Hospital readmissions in Europe [Internet]. Diepoldsau, CH: i-Magazine AG; 2013 [cited 2013 May 29]. Available from: http://www.yumpu. com/en/document/view/14608448/hospital-readmissionsin-europe.

8. Hackbarth GM, Reischauer R, Miller M. Report to the congress: Medicare Payment Policy. Washington, DC: Medicare Payment Advisory Commission; 2007.

9. Jencks SF, Williams MV, Coleman EA. Rehospitalizations among patients in the Medicare fee-for-service program. N Engl J Med 2009;360:1418-28.

10. Centers for Medicare and Medicaid Services. ReadmissionsReduction-Program [Internet]. Baltimore: Centers for Medi- 
care \& Medicaid Services; 2013 [cited 2013 Nov 29]. Available from: http://www.cms.gov/Medicare/Medicare-Feefor-Service-Payment/AcuteInpatientPPS/ReadmissionsReduction-Program.html.

11. Joynt KE, Jha AK. Characteristics of hospitals receiving penalties under the Hospital Readmissions Reduction Program. JAMA 2013;309:342-3.

12. Centers for Medicare and Medicaid Services. Application of incentives to reduce avoidable readmissions to hospitals. Fed Regist 2008;73:23673-5.

13. Vaduganathan M, Bonow RO, Gheorghiade M. Thirty-day readmissions: the clock is ticking. JAMA 2013;309:345-6.

14. American College of Surgeons, National Surgical Quality Improvement Program. User guide for the 2011 participant use data file [Internet]. Chicago: American College of Surgeons; 2012 [cited 2013 Apr 8]. Available from: http://site.acsnsqip. org/wp-content/uploads/2012/03/2011-User-Guide_Final.pdf.

15. Birkmeyer JD, Shahian DM, Dimick JB, et al. Blueprint for a new American College of Surgeons: National Surgical Quality Improvement Program. J Am Coll Surg 2008;207:777-82.

16. Sleijfer S, Van der Graaf WT, Willemse PH, et al. High-dose methotrexate, vincristine and cisplatin as salvage treatment for relapsed non-seminomatous germ-cell cancer. Anticancer Res 1995;15:1039-42.

17. Mioton LM, Buck DW 2nd, Rambachan A, et al. Predictors of readmission after outpatient plastic surgery. Plast Reconstr Surg 2014;133:173-80.

18. Harrop JS, Styliaras JC, Ooi YC, et al. Contributing factors to surgical site infections. J Am Acad Orthop Surg 2012;20:94101.

19. Beldi G, Bisch-Knaden S, Banz V, et al. Impact of intraoperative behavior on surgical site infections. Am J Surg 2009; 198:157-62.

20. Yost GW, Puher SL, Graham J, et al. Readmission in the 30 days after percutaneous coronary intervention. JACC Cardiovasc Interv 2013;6:237-44.

21. Blackledge HM, Squire IB. Improving long-term outcomes following coronary artery bypass graft or percutaneous coronary revascularisation: results from a large, population-based cohort with first intervention 1995-2004. Heart 2009;95:30411.

22. Krumholz HM, Merrill AR, Schone EM, et al. Patterns of hospital performance in acute myocardial infarction and heart failure 30-day mortality and readmission. Circ Cardiovasc Qual Outcomes 2009;2:407-13.

23. Ogunleye AA, de Blacam C, Curtis MS, et al. An analysis of delayed breast reconstruction outcomes as recorded in the American College of Surgeons National Surgical Quality Improvement Program. J Plast Reconstr Aesthet Surg 2012; 65:289-94.

24. Joynt KE, Jha AK. Thirty-day readmissions: truth and consequences. N Engl J Med 2012;366:1366-9.

25. Sellers MM, Merkow RP, Halverson A, et al. Validation of new readmission data in the American College of Surgeons National Surgical Quality Improvement Program. J Am Coll Surg 2013;216:420-7. 